\title{
Erratum to: Empathy, Einfühlung, and aesthetic experience: the effect of emotion contagion on appreciation of representational and abstract art using fEMG and SCR
}

\author{
Gernot Gerger $^{1} \cdot$ Matthew Pelowski $^{1} \cdot$ Helmut Leder $^{1}$
}

Published online: 12 April 2017

(c) Marta Olivetti Belardinelli and Springer-Verlag Berlin Heidelberg 2017

\section{Erratum to: Cogn Process}

\section{DOI 10.1007/s10339-017-0800-2}

Unfortunately, the given name and family name of the corresponding author Dr. Gernot Gerger were incorrectly published in the original publication. The correct given name and family name should read as 'Gernot' and 'Gerger', respectively. doi:10.1007/s10339-017-0800-2. 